\title{
Management status of agricultural plant genetic resources in Nepal
}

\author{
MN Paudel, BK Joshi and KH Ghimire \\ National Agriculture Genetic Resource Centre, Khumaltar \\ Email:mnpaudel@gmail.com
}

\begin{abstract}
Agricultural plant genetic resources (APGRs) are one of the pivotal sources for developing high yielding, stress tolerance varieties to sustain food and nutritional security of the world. Nepal has established National Agriculture Genetic Resource Centre (NAGRC), alias Genebank under the Nepal Agricultural Research Council (NARC) in Khumaltar premise in 2010 AD (2066 BS). NAGRC has been doing collection, identification, characterization, and regeneration of APGRs since its establishment. There are more than 11000 collections of APGRs in the Genebank. These accessions include cereals, pseudo cereals, pulses, oilseeds and vegetable of orthodox seed whereas crops having recalcitrant seed are conserved in the field Genebank, on-farm genebank and tissue bank. To analyze characters of new accessions, standard passport data are recorded and entered to accessions giving geographical locations and coordinates. The APGRs have been collected, cleaned, processed, preserved and regenerated and characterized according to the standard procedures and norms used by scientists across the world. Types of Genebank and options for effective management of APGRs in Nepal have explained in brief. This paper tries to explain the importance and management of APGRs with respect to sustain food and nutritional security of Nepal in coming days ahead.
\end{abstract}

Key words: agricultural plant genetic resources, genebank, collection, processing, characterization, regeneration

\section{Physiographic location and agro-ecological domain of Nepal}

Nepal is located in South Asia in coordinates of $28^{\circ} \mathrm{N}$ and $84^{\circ} \mathrm{E}$ and it is situated in between China in the north and India, in the east, west and south. Geographically Nepal is divided into five main regions; the Himalaya, high hills, mid-hills, Siwalik and, and Terai, however, agro-ecologically, Nepal is divided into (hills both high and mid), Siwalik and Terai. Nepal, noted for her majestic Himalayas, the roof of the world, Sagarmatha, the Mount Everest $(8848 \mathrm{~m})$ in the north and the lowest point Kechanakal $(60 \mathrm{~m})$ in the south. The Himalayas which in Sanskrit means the home of snow, the water towers, which supply water to the Indo-gangetic plain of Indian subcontinent, are the proud of the mountainous and hilly country, Nepal (Paudel and Sharma, 2009). Its shape is roughly rectangular, about 650 kilometers long and about 200 kilometers wide, and comprises a total of 147,181 square kilometers area. Climate of Nepal varies from cool summers and severe winters in north to subtropical summers and mild winters in south. 
Human beings are dependent on plant genetic resources for their diet. Globally, over $84 \%$ of human diet and nutrition come from plants while in Asia and the Pacific, the Near East and Africar regions, plants provide around around $90 \%$ of the average human diet (FAO, 2011). However, human beings are dangerously relying on only a few different crops. Out of the 10,000 to 12,000 known edible plant species, only 150 to 200 are used by humans and three of them alone are rice, wheat and maize contribute nearly $60 \%$ of calories and proteins requirements for humans obtained from plants sources (FAO, 2011).

\section{Brief history of biodiversity and establishment of Genebank in Nepal}

Collections of Nepalese PGRs were begun in 1802 by Buchanan Hamilton and it was continued by N Wallich up to 1820-21 (MoFSC, 2002). From this time onwards, Nepal has been well explored. As a result, different PGRs in general APGRs in particular were collected and conserved in both national and international genebanks. There are more than 100 organizations working on APGRs in Nepal. Internalizing valueand importance of APGRs, Nepal Agricultural Research Council (NARC), the main institution responsible for conservation of APGRs started management of agrobiodiversity through crop commodity programs and the National Agriculture Genetic Resources Center (NAGRC) formally in 1910. In this line, NARC under the Government of Nepal (GoN) has incepted the National Agriculture Genetic Resources Center (NAGRC, alias Genebank) in Khumaltar, Lalitpur in 2010 as well.

Nepal is called the micro-museum of world climate. There are climatic zones ranging from subtropical to tundra with a narrow band of altitude (Fig. 1). The climate of Nepal varies from subtropical to arctic, all within a distance of approximately 180 kilometers. In addition to the broad differentiations in climate, there is a great variety of micro climatic conditions, resulting in adversity of land use and land practices within the country. In general, the climate of the Terai, Dun valleys, and part of the Siwaliks (300-1000m) is subtropical. The climate of the middle mountains (1000-3000m) ranges from warm temperate to cool temperate, and the high mountains (2600-4200m) from cool temperate to sub-alpine (Paudel and Sharma, 2009). The climate of mountain region is pleasant and amicable for many flora and fauna. Above mountain region there is Himalaya $(>4200 \mathrm{~m})$ and which is represented by tundra and high alpine climate. Nepal, compared to her geographical size, encompasses a wide range of physiographic regions, ecosystems and vegetation from flat lowlands to steep mountain slopes which is endowed with $0.1 \%$ of earth's land mass and harbors $2.2 \%$ of flowering plants, $1.4 \%$ of reptiles, $2.2 \%$ of fishes, $8.5 \%$ of birds, $4.2 \%$ of butterflies and $4 \%$ of mammals of the world (BPP, 1995). The country has high levels of biodiversity. Figure 2 depicts diversity of agro-ecological zones and farming systems in Nepal (Gauchan and Shrestha, 2015).Because of such a varied agro-ecological dimension with respect to climate, flora and fauna Nepal is the $10^{\text {th }}$ richest country for agricultural biodiversity in Asia. She has 7000 flowering plant species that 
makes her one of the global hotspots for both natural and agricultural biodiversity. Among them 370 species are endemic and about 600 food plants species have been estimated to be grown within the altitude range of $60 \mathrm{~m}$ to $4200 \mathrm{~m}$ above sea level (MoFSC, 2002; Upadhyay and Joshi, 2003 (Fig. 2).

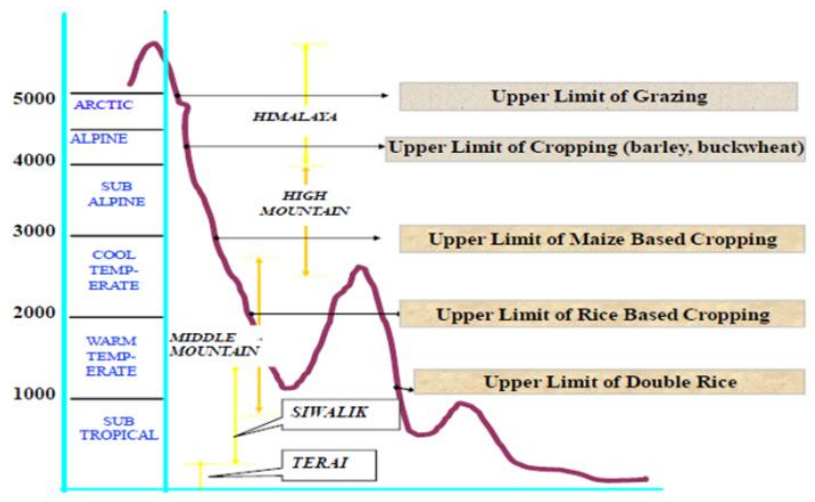

Fig. 1 Diversity of agro-ecological zone and farming systems in Nepal

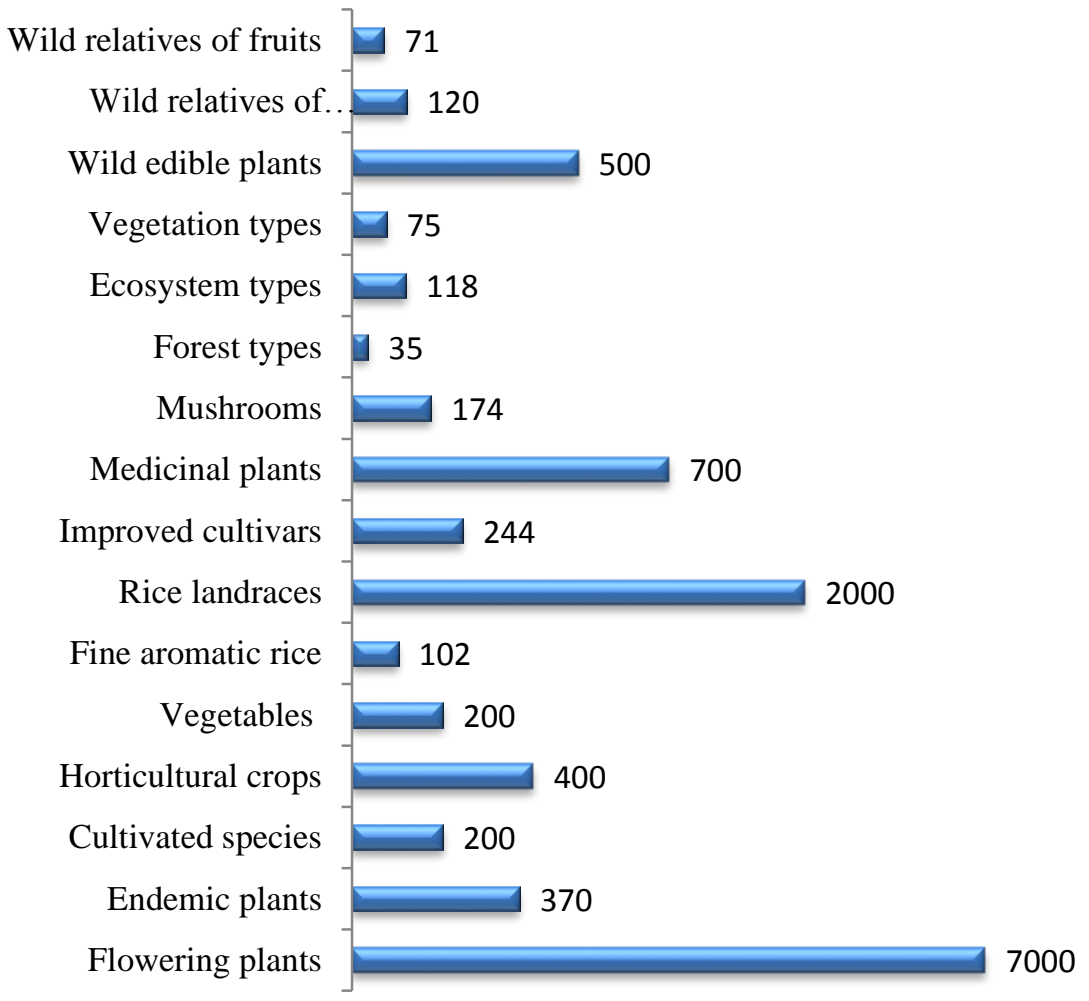

Fig. 2 Plant biodiversity status in Nepal 
Nepal is blessed with rich diversity in cereals, grain legumes, vegetables, fruits and other crops as well. Up to now there are at least 4 species of wild rice named Oryzanivara, $O$. rufipogon, O. granulata and O. officinalis, two wild relatives of Hygroryzaaristata and Lersiahexandra and several types of weedy rice such as $O$. sativa $f$. spontanea exist in Nepal and there are probability of getting still more species of rice and other food crops. Wild relatives of wheat are available in the hilly and mountainous region. Aegilops and Agropyrum species of wheat have been documented. The genetic diversity in high hill has been maintained due to specificity of landraces, undisturbed forests, fragility and inaccessibility. In Terai there are swamps and lakes such as Kapilbastu in western and Banke and Kailali in mid and far western Terai the level of genetic erosion is observed maximum for major crops because of human intervention in such natural habitat for bringing them under cultivation and for agriculture and aquaculture purposes. Many indigenous rice landraces like Anadi, Tauli and Thapachiniya are vanishing from general cultivation. Overall diversity of major crops is in decreasing trend and genetic erosion is apparently visible (Joshi et al; 2008, Bhatta et al; 2014). Available information indicates among its 60 reported species of Ameranthus in the world at least 11 species (cultivated, for grain and green vegetables, wild and weedy types) have been reported in Nepal. Among 32 species of Hordeum described around the world, three species have been reported. Hordeum vulgare is the only cultivated species and the rest two are wild type. Covered and naked barley are commonly available and used for diverse purpose including religious use by rural and urban community in Nepal. Diversity in buckwheat (Fagopyrum sp.), naked barley (Hordeum vukgare var. nudum L.), and finger millet (Eleusine sp.) in wild and cultivated form have been found abundantly indicating their centre of origin in Nepal.

Equal diversity of vegetable crops has been recorded in Nepal. These include wild relatives of Colocasia (three spp.), Amaranthus (four spp.), Chenopodium (two spp.), Rumex (three spp.), Pisum (three spp.), Alium (three spp.), Ipomoea (five spp.), Dioscorea (four spp.), Mentha (three spp.), Trigonella (two spp.), Solanum (two spp.), and Curcuma (five spp.). Nine species of Prunus, three species each of Castanopsis, Malus, Morus and Rubus and two species each of Barberies, Ficus, Hippophae, Olea, Pyrus and Vitis are documented as temperate wild fruit relatives. Similarly, subtropical and tropical wild fruit relatives having more than one species are Annona, Citrus, Mangifera, Musa, Foenix and Rhus. There are reports of availability of wild relatives of many subtropical and temperate crops including apple, plum, walnut, pear, olive, and sea-buckthorn and many more in Nepal. 


\section{National Genebank}

APGRs are the creation of nature for sustaining food, fiber, cloths, medicine, and energy to sustain lives in the world. It is the utmost importance of every country to conserve and utilize APGRs for present generation without compromising the utilization of the future generation as well. After the establishment of Genebank in under NARC in Khumaltar, Lalitpur in 2010, the GoN has initiated formally management of APGRs for sustaining food and nutritional security in Nepal. The underlying discussion shed light on information about Genebank, its mission and objectives, collection, characterization, preservation, regeneration and utilization of PGRs, and issues thereby objectives of Genebank could be achieved to meet the ever projecting food and nutritional security of Nepalese in coming days.

Management of APGRs is the regular activities undertaken by the NAGRC (Genebannk), Nepal. Recentrly, Nepal Agricultural Research Council (NARC) under the Government of Nepal (GoN) realized the importance of PGRs. Accordingly, the National Agriculture Genetic Resources Center (NAGRC), Genebank, was established in 2010 (2066 BS) for conservation and utilization of agro-biodiversity. Genebank establishment is the milestone in supporting food and nutritional security and national economic development to meet the national obligation of implementing international agreements (the Convention on Biological Diversity (CBD), 1992 and International Treaty on Plant Genetic Resources for Food and Agriculture (ITPGRFA), 2004). An area of 2.4 ha is allocated for genebank in Khumaltar premise. Out of 2.4 ha, Genebank building has occupied 0.092 ha, 0.26 ha is allocated for Field Genebank and 0.83 ha for regeneration, multiplication, characterization, evaluation and post quarantine activities of PGRs. The Centre has considered the diverse strategies of ex-situ, on-farm and in-situ management of agricultural genetic resources (Joshi et al; 2012). In addition to these strategies, Genebank has encouraged other existing supplementary mechanisms for conserving agro-biodiversity in Nepal. Existing supplementary mechanisms are associated to religious practices of Hinduism and Buddhism with regards to some plants, culturally protected areas (temple and other religious heritages), leasehold, and community forests where PGRs have been protected in these heritages areas.

Realizing the importance of PGRs conservations, NARC in 11 March 2014 deposited 69 (sixty nine) barley accessions in the World Seed Vault, established under the Rural Development Administrtaion (RDA) at the National Agrobodiversity Center (NAC) of the National Academy of Agriculture Science (NAAS) in Suwon, Republic of Korea, 2006. This World Seed Vault has been recognized by the Global Crop Diversity Trust (GCDT) in 2008 as a hub-bank by offering safety duplication service (black-box type) free of charge of germplasms of foreign countries in harmony with GCDT (AFACI-Nepal Newsletter, 2014). 
Following facilities have been created in the Genebank with the support of GoN and other donors:

Long term storage/ Base collection room: Collections are stored at $-18^{\circ} \mathrm{C}$ with a relative humidity of 40\% for 50-100 years. Seed moisture is lowered to 3-7\% depending on crop species. Size of accession is about 2000 seeds for self-pollinated crops and 4000 seeds for cross-pollinated crop species.

Medium term storage/: Cold Store Room (Active Collection Room, ACR) with 4-10 ${ }^{\circ} \mathrm{C}$ and 35-45\% RH for storing about 50,000 accessions for 5-10 years.This is ex-situ conservation (Seed Bank) for orthodox seeds /active collections (working or core collections): Collections are stored at 5 to $10^{\circ} \mathrm{C}$ with a $\mathrm{RH}$ of $30-40 \%$ for $5-15$ years. This system of seed storage is also called short term storage system and used to characterize, evaluate, multiply and distribute stored seeds for clients demanding seeds for R\&D purpose within the country. Accessions size is about 4000 seeds for self-pollinated crops and 8000 seeds for cross pollinated crops.

In-vitro cultural lab and tissue bank: There is a facility for tissue culture and tissue bank with a capacity of 50,000 preserving samples of recalcitrant seed.

Molecular research lab: Facility for DNA works e.g. genotyping, genetic diversity assessing, identification (DNA fingerprinting, marker assisted selection), gene mapping and tagging are available.

Field Genebank: This is essential for those crop species which are having recalcitrant seed types and vegetatively propagated and apomictic crop species meant for their conservation, characterization, evaluation and utilization. In theis system, government's farm in area around the road and office buildings, community farms, botanical garden, culturally protected heritage sites are considered suitable locations for field genebank. Aside from this, field plots within Khumaltar under NARC along the road and around the office buildings and premises are also considered as field genebank.

Seed testing and processing lab: This under pins facilities for seed cleaning and seed health testing, viability testing, drying, and characterizing seeds.

Experimental plot: This includes experimental fields for diversity blocks used for regeneration, multiplication, characterization, and evaluation of PGRs.

Database management: Under this, facilities are created for passport data management, characterization, evaluation, pre-breeding, genotyping; and utilization of PGRs data for various R\&D purposes.

On-farm conservation: This is a dynamic conservation of local and important crop varieties. Genebank has been supporting on-farm conservation since 2001 by involving farmers to conserve their genetic resources in their field by establishing Community Seed Bank (CSB) in Kachorwa, Bara (2003) and Simariya, Sunsari (2011) by enhancing management of landraces in the community level. In 1994, for the first time in Nepal, 
Dalchowki of Lalitpur Comminity Seed Bank was initiated to strengthen management of local land races in the community by collecting and storing PGRs in the CSB. Similarly, seed diversity fairs and diversity blocks were the the major activities to collect and maintain the varietal diversity in CSB. Now, there are many CSBs established across different agro-ecological domains in the country. Establishment of CSBs is taking momentum by the regular program under DoA. Around a dozen CSBs are running functionally in Nepal with technical support from Genebank and DoA.

In-situ conservation: This is for wild edible plants and wild relatives of cultivated crop species. The sites where, important wild edible plants and wild relatives exist are planned to conserve in collaboration with National Parks, religiously and culturally protected sites, heritage sites and community areas including different types of forest management such as lease hold forest and community forest managed by public and private institutions and communities. It needs to locate species that needs to be conserved and develop strategies to protect their habitat collaborating with relevant stakeholders.

\section{Mission and objectives of Genebank}

The mission of genebank is conservation and utilization of all kinds of agricultural genetic resources for food and nutritional security, livelihood enhancement, and economic growth of Nepal.

\section{Objectives}

- Eexplore, collect and conserve agricultural genetic resources for promoting sustainable use,

- manage and handle the agricultural genetic resources scientifically in the country according to the rules and regulations of GoN with respect to genetic resources movement,

- dentify the endangered, rare and unique genetic resources and give emphasis to conserve them,

- create a single entry point to get access to AGRs and associated data,

- locate the centre of diversity of all economic crop species in the country,

- characterize including DNA finger printing and evaluate genetic resources and avail resources to researchers, academicians, farmers, entrepreneurs, and related stakeholders, and

- screen genetic resources and identify markers associated with particular traits and develop elite lines through pre-breeding, and manage database associated with each accession including passport, characterization, evaluation and traditional knowledge. 


\section{Acquisition of germplasms}

NAGRC has regularly conducting the PGRs exploration and collection missions to different parts of the country since 2010 . Until 2015, about 7,300 accessions of more than 100 crop species were collected from 62 districts out of 75 districts (Fig.3 and Table 1) (Genebank 2011, 2012, 2013, and 2014). On 25 ${ }^{\text {th }}$ April 2015 the massive earth quake shook Nepal is general and 15 of the 75 districts. There was huge loss of PGRs caused the massive earthquake of 2015. Rescue collection of seed in the major devastated districts is going on and seeds have been collected to further conserve them for future use in locations where these are native to.

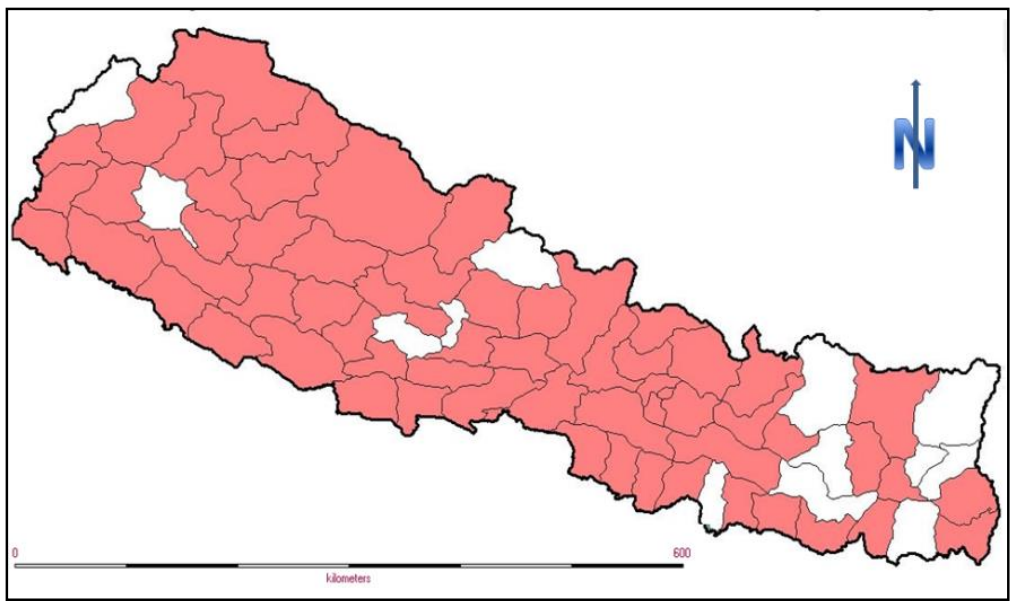

Fig. 3 Map of Nepal showing PGR exploration and collection districts from 2010 2015

Table 1. Exploration \& Collection of PGRFA by NAGRC from 2010 - 2015

\begin{tabular}{llll}
\hline Year & $\begin{array}{c}\text { Number of } \\
\text { districts }\end{array}$ & \multicolumn{1}{c}{$\begin{array}{c}\text { Number of } \\
\text { crops }\end{array}$} & Number of Collections \\
\hline $2010-11$ & 13 & 63 & 1322 \\
$2011-12$ & 8 & 60 & 1346 \\
$2012-13$ & 18 & 50 & 2011 \\
$2013-14$ & 21 & 40 & 993 \\
$2014-15$ & 16 & 30 & 1627 \\
\hline Total & $\mathbf{6 2}$ & $\mathbf{4 9}$ & $\mathbf{7 2 9 9}$ \\
\hline
\end{tabular}




\section{Characterization of germplasm}

There were a total of 10,781 old accessions. Among them, only 3126 accessions were regenerated and 5505 were found non-viable. Most of the accessions which were kept for regeneration and multiplication were characterized and evaluated using standard descriptors. For characterization, field books were prepared based on the descriptors developed by the Bioversity International and national requirements. The characterized and multiplied accessions were 3498 and 2604, respectively for 15 crops (Figure 5) whereas the number of germplasm characterized only were 8581 for 46 crops up to 2014/15 (Table 2). The number of accessions characterized and evaluated for crops is given (Figure 5). Both phenotypic and genotypic data will soon be available for most of the collections under the Genebank.

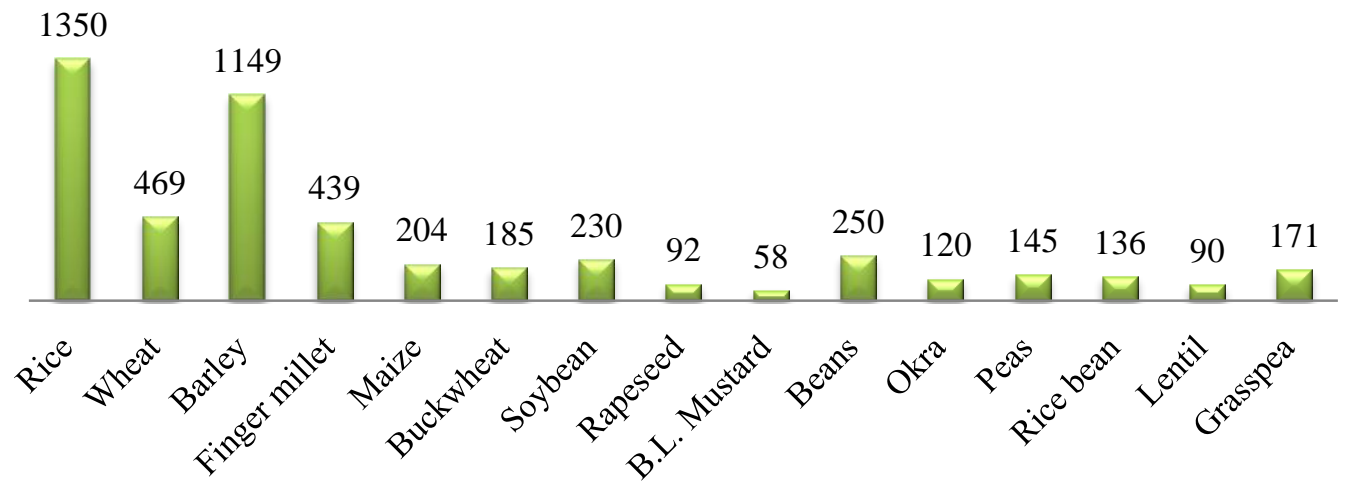

Figure 5. Number of germplasm characterized and evaluated for different crops by the Genebank, Nepal

Trait distribution study to identify unique genetic resources: During characterization, trait distribution across the landraces has been studied. If trait is found only in a particular landrace, this landrace is grouped as unique. There are many such types of landraces and some of them are given (Table 2).

Table 2. Unique agricultural plant genetic resources reported in Nepal

\begin{tabular}{|c|c|c|c|}
\hline Crop & Landrace & & Uniqueness \\
\hline \multirow[t]{5}{*}{ Rice } & Gamadi & & $\begin{array}{l}\text { Panicle matured within flag leaf without exertion } \\
\text { outwardly }\end{array}$ \\
\hline & Mansara & & Adopted to very marginalized land \\
\hline & Bhati & & Deep water rice \\
\hline & $\begin{array}{l}\text { PakheMasino, } \\
\text { Kandhu }\end{array}$ & Makar & Hiunde (winter) rice \\
\hline & Ekle rice & & Zn deficiency tolerance \\
\hline
\end{tabular}




\begin{tabular}{lll}
\hline Crop & Landrace & Uniqueness \\
\cline { 2 - 3 } & JumliMarshi & Cold tolerant high altitude (3050m) cultivation rice \\
\cline { 2 - 3 } Wheat & Amaghauj & Multiple spikelets per node \\
\cline { 2 - 3 } & Mudule & Very sweet tasted wheat \\
\hline Finger millet & Dailekh Local & For low fertility and moisture deficient condition \\
\hline Naked barley & Karu/Uwa & $\begin{array}{l}\text { Naked (hull less) barley cultivated in high altitude } \\
\text { range of mountain }\end{array}$ \\
\hline Cauliflower & $\begin{array}{l}\text { Dalchwoki Local } \\
\text { Kauli) }\end{array}$ & Very large head, perennial in nature \\
\hline Chilly & Jire & All year round fruiting \\
\cline { 2 - 3 } & Ranga/ Akabare & Medicinal value and very hot \\
\hline Yellow & Ghorli Kharka & High oil content \\
Sarson & Bhate Phaper & Loose husk good for cooking without grounding \\
\hline Buckwheat & Kagpani, Tatopani & Highest rutin content \\
\cline { 2 - 3 } & & \\
\hline
\end{tabular}

Duplicates identification: Duplicate identification and merging them have been started. For this, passport descriptors of all subjected accessions are compared. Then team of Genebank visit field to look the similarity among accessions. Genebank has planned to use the following data for identification of duplicates.

- Phenotypic and genotypic data

- Standing crop inspection

- Group discussion including farmers

\section{Regeneration of germplasm}

Since 2010 to date, a total of 7962 accessions of 49 crops were regenerated whereas a total of 8581 accessions of 46 crop species were characterized and evaluated (Table 3). Genotyping and diversity assessment of germplasm have also been initiated using molecular techniques at national genebank (Genebank 2011, 2012, 2013, and 2014).

Table 3. Number of crops and accessions regenerated and characterized from 2010 to 2015

\begin{tabular}{lllll}
\hline \multirow{2}{*}{ Year } & Regeneration & \multicolumn{3}{c}{ Characterization } \\
\cline { 2 - 5 } & No of crops & No of accessions & No of crops & No of accessions \\
\hline $2010-11$ & 3 & 861 & 3 & 1536 \\
$2011-12$ & 9 & 1462 & 7 & 1342 \\
$2012-13$ & 22 & 3414 & 12 & 2697 \\
$2013-14$ & 15 & 2225 & 11 & 2249 \\
$2014-15$ & - & - & 13 & 757 \\
\hline Total & $\mathbf{4 9}$ & $\mathbf{7 9 6 2}$ & $\mathbf{4 6}$ & $\mathbf{8 5 8 1}$ \\
\hline
\end{tabular}




\section{Conservation of germplasm}

The agro-biodiversity in Nepal is directly related to the livelihoods of Nepalese people. Since biodiversity is shrinking rapidly in recent decades, the global concern is to conserve and sustainably use the valuable genetic resources for the betterment of the people and address the challenges posed by climate change. More than 23,000 germplasm from Nepal have been conserved in the Genebank of 12 countries. The GoN and NARC have prioritized conservation and sustainable use of agro-biodiversity. Realizing the significance of long-term conservation of agricultural plant genetic resources for food security, GoN has established NAGRC, genebank under NARC in September 2010 with the mission of conservation and sustainable use of agricultural genetic resources for sustained agricultural growth and livelihood enhanvement. In 2014, sixty nine barley accessions of Nepal have been safety duplicated in the world, Seed Vault, Suwon, Korea (AFACI-2014).

Large degree of genetic erosion is evident in major food crops that are the basis of food and nutrition security and livelihood of Nepalese. It is estimated that $50 \%$ of traditional varieties have disappeared from farmers' field and existing landraces could be in the endangered condition. Currently, breeders are facing problem to obtain diversity from exotic and indigenous sources. Farmers, students and researchers have limited options to work with genetic resources because of unavailability and poor access of these potential genetic resources to be used for crop improvement and curb down inects, pests and diseases occurance in the modern, potential, and adopted varieties of food crops, because PGRs are the bed rock of modern agriculture and natural resource management.

Considering value and importance of genetic resources that are being considered for conservation are landraces, modern varieties, obsolete varieties, breeding lines, recombinant inbred lines (RILs), genetic stocks, near isogenic lines (NILs), differential lines, exotic genetic resources, wild and wild relatives and endemic accessions of wild edible plants. These genetic resources are grouped based on the economic values as cereals, millets, pulses, vegetables, fruits, fibers, oil seeds, spices and beverages. Based on the conservation strategy, all agricultural genetic resources are grouped as orthodox seeds (can dry up to 3-7\% moisture depending upon crop species), recalcitrant seeds (can't dry lower than $12-31 \%$ moisture) and vegetative propagated crops and apomictic plants.

\section{Ex-situ conservation at NAGRC}

National genebank holds more than 11,000 accessions of about 110 crop species with their passport data. Among them 5,850 accessions of cereals, 1,150 accessions of pseudo cereals, 1,800 accessions of pulses, 185 accessions of oilseeds and 565 accessions of vegetable crops are preserved at NAGRC and 301 accessions of various crops are conserved in the field genebank (Table 4). 
Table 4. Number of accessions under $e x$-situ conservation at Nepal Genebank

\begin{tabular}{|c|c|c|c|c|c|}
\hline $\mathbf{S N}$ & Crop & No of accessions & SN & Crop & $\begin{array}{c}\text { No of } \\
\text { accessions }\end{array}$ \\
\hline 1 & Rice & 2,400 & 24 & Tomato & 20 \\
\hline 2 & Wheat & 1,700 & 25 & Pumpkin & 50 \\
\hline 3 & *Barley & 1,230 & 26 & Okra & 125 \\
\hline 4 & Maize & 520 & 27 & Bitter gourd & 15 \\
\hline A. & Cereals & 5,850 & 28 & Sponge gourd & 20 \\
\hline 5 & Millets & 670 & 29 & Balsam apple & 25 \\
\hline 6 & Buckwheat & 230 & 30 & Lettuce & 10 \\
\hline 7 & Amaranths & 200 & 31 & Brinjal & 25 \\
\hline 8 & Sorghum & 50 & 32 & Cucumber & 40 \\
\hline B. & Pseudo cereals & 1,150 & 33 & Leaf mustard & 30 \\
\hline 9 & Lentil & 300 & 34 & Coriander & 25 \\
\hline 10 & Chickpea & 300 & 35 & Cress & 30 \\
\hline 11 & Cowpea & 150 & 36 & Chilli & 100 \\
\hline 12 & Grass pea & 120 & 37 & Radish & 50 \\
\hline 13 & Pigeon pea & 20 & E. & Vegetables & 565 \\
\hline 14 & Field peas & 125 & 38 & Taro & 30 \\
\hline 15 & Beans & 430 & 39 & Yam & 15 \\
\hline 16 & Kidney/broad bean & 45 & 40 & Ginger & 80 \\
\hline 17 & Soybean & 150 & 41 & Turmeric & 75 \\
\hline 18 & Rice bean & 40 & 42 & Chayote & 15 \\
\hline 19 & Black/horse grams & 120 & 43 & Potato & 10 \\
\hline C. & Pulses & 1,800 & 44 & Sugarcane & 6 \\
\hline 20 & Rapeseed/mustard & 110 & 45 & Garlic & 50 \\
\hline 21 & Sesame & 40 & 46 & Fruit trees & 20 \\
\hline 22 & Niger & 15 & F. & Field Gene Bank & 301 \\
\hline 23 & Linseed & 20 & 47 & Others & 1,200 \\
\hline D. & Oilseeds & 185 & Tota & & 11,051 \\
\hline
\end{tabular}

*Sixty nine accessions of barley from Nepal have been safety duplicated in the World Seed Vault, Suwon, Korea in 2014

\section{Utilization of germplasm}

Genebank facilitates for utilization of germplasm by providing easy access and databases, strengthen utilization with elite line development, collaborative marker assisted selection, tagging and mapping genes, screening germplasm, pre-breeding works and collaborations. The total accessions distributed are 406 of 8 crops up to 2015 (Fig.5). 


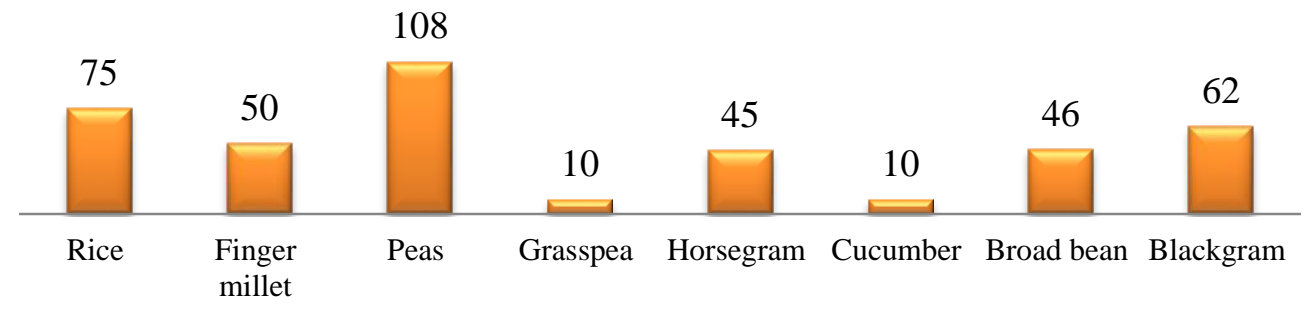

Fig. 6 Accessions distributed for research from genebank up to 2015

\section{Issues of germplasms management in Nepal}

Despite knowing the importance of PGRs, there are some pertinennts issues to be taken into consideration for effective management of PGRs in Nepal. Some of the important issues are discussed briefly below for successful mnnagement of PGRs in Nepal:

\section{Repercussion of April 25, 2015 devastating earthquake and its aftermath}

Nepal faced devastating effect of April $25^{\text {th }}$ earthquake measuring 7.8 in the Richter scale, however some unofficial claim is that the earthquake was 8.1 Richter scale, and its subsequent after shock. Up to now more than 436 (as of $9^{\text {th }}$ March 2016) earthquake of magnitude greater than 4 Richter scale are frequently shaking Kathmandu valley and periphery. Genebank building is partially damaged due to these earthquakes. If similar scale's earthquake hits Nepal there is the possibility of destruction of genebank and its structure. Therefore, immediate attention should be given to protect collected PGRs against natural calamity. Conservation building should be retrofitted and be made strong enough to absorb the shocks in area of damage without delay and safety duplication of collected accessions in other location of the country should also be considered.

\section{Awareness creation among farmers}

PGRs area maintained and conserved by the farmers since time immemorial, however, it has been, sometime, a hilarious task to convince them that PGRs should be conserved in genebank for future and present generation's use. Therefore, PGRs should be provided free of cost. Due to involvement of some activists with respects to PGRs, farmers sometime are reluctant to provide information and seed samples to collectors even for Genebank as well.

\section{Collections from standing crops}

Due to rugged terrains, inaccessible and remoteness of agro-ecological regions of Nepal, collections of PGRs could not be done from the standing crops and most of the collections are from farm store. Effective collections are from standing crops to capture diversity as much as possible, to identify the samples and to get enough seeds so that collections can be directly conserved in short and long term storage without multiplication of their seed immediately after collection. This could save resources. 


\section{Creation of favourable environment for regeneration}

Artificial facilities in glass house by maintaining favourable temperature, sunshine hours and moisture are appropriate condition for regeneration of PGRs in ex-situ condition. Presently this facility is not prevailed in Genebank as a result effective regeneration could not be done in Khumaltar condition.

\section{Restrain of sufficient diversity}

There is a need of collecting sufficient number of seeds of rare and endangered species from the farmers especially of vegetables and small seeded crops. Collections are generally made from farm store. This makes our (genebank) business more difficult due to limited amount of seed available for conservation. As a result, there is difficult to maintain sufficient diversity from collection and genebank has to multiply the seeds of such species collected from farm houses to put under conservation.

\section{Collection of duplicate samples}

It is extremely difficult to differentiate between original and duplicate samples because name of same land races could be different based on collection from different ethnic community. Variation of name of same land race may differ within even in a same village with different ethnic group and with people speaking different dialects. In such situation, there may be collection of many duplicate samples of same land races. Under such circumstances, molecular identification and genotypic verification could be alternative to lessen duplicate sample. This requires skilled manpower and cost associated on it. In some cases, donors and recipients may place emphasis on increasing the number of accessions, which leads to collect many samples within limited areas and from a few farmers increasing number of duplicate samples which increases cost and burden for their maintenance.

\section{Manpower}

Due to the limited manpower, collections and regeneration activities have not been become effective and efficient. There is an immediate need of taxonomist; breeder and plant pathologist to effectively carry out grow out tests, disease screening and characterization of traits associated with breeding and conservation, characterization, and multiplication of PGRs.

\section{Setting of seed}

Many accessions of rice and grain legumes regenerated in Khumaltar-Kathmandu and Rampur-Chitwan could not set seeds. This may be due to variation in temperature and variation in photoperiodism because of change in location and season. Appropriate locations need to identify for regeneration of different accessions. This can be solved using the passport data and GIS information but many of accessions of old collections do not 
have complete passport data and GIS information.

\section{Viability of old collection samples}

Many of the old collections were found non-viable (Bhatta, 2012). It needs to revisit the locations for collections samples using available information of passport data and GIS information.

\section{Sample identification}

Nepal is rich in plant diversity and ethnic diversity. As a result, PGR samples collected are difficult to identify because of limited knowledge on taxonomy and local dialects which are more than 100 in the country. Collectors are frequently facing problems on recognizing the samples in the field as well as farmers' given samples. Same sample is known differently in different ethnic community in different dialects.

\section{Seed health}

Due to infection of disease and infestation of insect and pests, seed health testing has not been started. This has created possibility of damage to seeds thereby there could be problems of regenerating collected PGRs.

\section{Standard sampling method and sites for specific samples}

Due to the lack of clear guidelines applicable to different crop species for sampling and locations, collectors always face problem for identifying sampling sites and sampling methods for different crops concerned.

\section{Conclusions}

NAGRC should be made functionally responsible for characterization, evaluation and tagging of economically important traits which should be recognized as a milestone foundation to strengthen pre-breeding and utilization of plant genetic resources in breeding and variety development by using these valuable and important genetic resources to sustain food and nutritional security of Nepal. Community Seed Banks in Nepal are now facing problem of sustainability due to withdrawal of support from NGOs. GoN and concerned agencies should commit untiring support to mobilize CSBs for exploration and collection, regeneration and multiplication of local as well as wild plant genetic resources. Database sharing among Asian countries is very weak and exchange of germplasm is even poor. The help and cooperation extended from different donor agencies be made more supportive than ever to facilitate PGRs management and information exchange/sharing among different countries. Exchange visits of scientists/technicians and experts from different countries should be continued to enhance the technical knowledge and regional collaboration for effective management of PGRs with new enthusiasms because Genebank in Nepal is passing through infancy stage. There are lot of to do checklists to improve 
functionality and modality of Genebank tailoring with international standard by sharing experience of developed countries empowering scientists working for Genebank of Nepal. The support for international training workshops to enhance the scientific capacity of the personnel working for Genebank should be further expedited in coming days to meet the challenge faced by the Genebank for managing PGRs in a scientific way. Such support should be directed to address study on molecular markers and infrastructure development for Cryo-bank in coming days as well. Most of old collections (collections before 2010) need to regenerate and it is necessary to recollect them from the old collection sites due to non-viability of old collections. Nepal, being remote and inaccessible in general and particular to hills and mountain where there is existence of land races to be collected properly and timely by using GIS tools and location tracking of whereabout of important and endangered PGRs. PGRs should be fully utilized by breeders to develop varieties suitable for different agro-ecological niches of the country. However, there is the poor utilization of genetic resources due to limited information on plant genetic resources (need to characterize) mainly because of poor governance mechanism of PGRs which is coupled with limited traits information both at phenotypic and genotypic levels. Hence, it is needed to conserve all kinds of PGRs encompassing orthodox types, recalcitrant types and vegetative propagated crop species as well.

\section{References}

AFACI (Asian Agriculture and Food Coperation Initiatives) -Nepal Newsletter. 2014. Published by the Agriculture Technology Information Network in Asia (AITN) of AFACI at the Ministry of the Agriculture Development (MoAD) Singhdurbar, Kathmandu, Nepal, Issue No. 1, August 2014, pp 4.

Bhatta, MR. 2012. Status of plant genetic resources (PGR) management system in Nepal. AFACI Pan-Asia Project Meeting, 19-22 March 2012. NAAS, RDA, Korea. Pp. 112124.

Bhatta, MR; KH Ghimire; BK Joshi; D Singh; M Bhattarai; and SK Shrestha. 2014. Exploration, regeneration and conservation of endangered cereals, grain legumes from Central Mid and High Hills of Nepal. In AFACI Expert Workshop and Planning Meeting for IMPGR, AFACI Pan-Asia Project, 25-29 Aug 2014, Sri Lanka. pp.183210.

BPP (Biodiversity Profiles Project). 1995. Biodiversity profile of the high mountain/high himal physiographic zones. Biodiversity profile project, Publication no. 14, Department of National Parks and Wildlife Conservation, Kathmandu.

FAO (Food and Agriculture Organization). 2011. Introduction to the international Treaty on Plant Genetic Resources for Food and Agriculture.FAO, Rome. 
Gauchan, D and S Shrestha. 2015. Agricultural and Rural Mechanization in Nepal: Status, Issues and Options for Future. Proceedings of the Workshop on Rural Mechanization: Policy and Technology Lessions from Bangladesh and other Asian Countries, 7-8 March, 2013 Dhaka, Bangladesh.

Genebank. 2011, 2012,2013, and 2014 . Annual Report 2067/68 (2010/11), 2068/69 (2011/12), 2069/70 (2012/13), 2070/71 (2013/14) and 2071/72 (2014/15). National Agriculture Genetic Resources Center, NARC (BK Joshi, KH Ghimire and SK Shrestha (eds). Khumaltar, Nepal.

Joshi et al. 2013. Reference guidelines for exploration and collection of agricultural genetic resources in Nepal. Genebank-NARC, Khumaltar, Lalitpur.

Joshi, BK. 2005. Rice gene pool for Tarai and Inner Tarai areas of Nepal. Nepal Agric. Res. J. 6:10-23.

Joshi, BK; HB KC; RK Tiwari; P Shrestha; R Amagain; and MP Upadhyay. 2005. Varietal richness of agricultural crop species and farmers' preferred traits over space and time in Nepal. Botanica Oreintalis (Journal of Plant Science) 5: 69-74.

Joshi, BK; MP Upadhyay; BK Baniya; and D Gauchan. 2012b. Area and diversity of a crop reflects the diversity of others. J. Agric. Environ. 13:5-8.

Joshi, BK; HB KC; MP Uadhyay; SR Gupta; BR Lu; and PN Mathur. 2008. Ex-situ and in-situ management of wild and weedy rice in Nepal using a geographical information system. Plant Genetic Resources Newsletter 155: 69-74.

MoFSC (Ministry of Forestry and Soil Conservation). 2002. Nepal Biodiversity Strategy, MoFSc, His Majesty's Government, Nepal.

Paudel, MN and NK Sharma. 2009. Prospects and limitations of hill agriculture systems sin Nepal. Proceedings of the Regional Workshop on Hill Agriculture in SAARC Countries: Constraints and Opportunities, 3-5 November, 2009. Compiled and edited by HemalFonseka, SAARC Agriculture Center, Bangladesh, Pp 85-93.

Upadhaya ,MP and BK Joshi. 2003. Plant Genetic Resources in SAARC Countries: Their Conservation and Management: Nepal Chapter. SAARC Agriculture Information Centre. pp.297-422. 